\title{
Introducing Research Letters to Boundary-Layer Meteorology
}

\author{
J. R. Garratt • E. Fedorovich
}

Received: 22 December 2014 / Accepted: 22 December 2014 / Published online: 9 January 2015

C Springer Science+Business Media Dordrecht 2015

For most of its 44 years, Boundary-Layer Meteorology has published Research Articles, Research Notes, and occasional Comments and Replies in hard-copy issues, but only in recent years has online publication become a reality. The online publication now precedes the appearance of articles in regular issues by several months and significantly expedites the delivery of new research results to journal readers. As of January 2015, in line with many science journals, including many of those published by Springer, we have added to our journal a new category of articles-Research Letters. This category is designed to provide a more rapid route to online publication with an initial review period of no more than one month. Boundary-Layer Meteorology now includes three main sections-Research Letters, Research Articles, and Notes and Comments. As with its host publication, Research Letters serves as an outlet for the exchange of ideas among scientists representing a variety of disciplines, all with an interest in boundary-layer meteorology and working on related research problems. In addition to rapid online publication, accepted Research Letters will appear within regular issues of Boundary-Layer Meteorology ahead of Research Articles and Notes and Comments to signify the importance of Research Letters as prestigious scientific publications.

The Research Letters section comprises short articles whose value is enhanced by rapid dissemination. They report on, (i) new findings of timely and compelling interest to the boundary-layer meteorological research community; (ii) notable early results from experimental, observational, model, and theoretical studies that are specifically suitable for brief communication; (iii) preliminary research findings likely to be highly valuable to the scientific community; (iv) significant extensions of earlier work. The Letters format is chosen, on the one hand, to ensure the immediate influence of the reported results on ongoing research and, on the other hand, to expose these results to prompt assessment by peers. This format underlies the potential of Research Letters to stimulate novel directions in boundary-layer meteorolog-

\footnotetext{
J. R. Garratt

CSIRO Marine \& Atmospheric Research, Aspendale, Australia

E. Fedorovich $(\varangle)$

University of Oklahoma, Norman, OK, USA

e-mail: fedorovich@ou.edu
} 
ical research. The main objective of Research Letters is to disseminate new research results significantly quicker than is the case of Research Articles. Each Letter is limited in size to five journal pages (approximately 4000 words) including no more than three figures, and must contain no supplementary online material. Editorial decisions on Research Letters will be based on an accelerated and streamlined peer-review process. Time from initial submission of an editorially acceptable article to online publication will typically be three to six months, with initial reviews obtained within one month. Revised manuscripts must be returned within one month of the Editor's recommendation and reviews being sent to the authors. If any of the Letters' criteria are not met, the submitted article will be considered for publication in the category of Research Article or Notes and Comments. Initially we aim to test the concept of Research Letters through 2015 and 2016, and invite readers and past authors to submit articles for this section forthwith. Authors should include in their cover letter a statement justifying the need for rapid publication against the criteria set out above. Any comment on a Letter should be submitted to the Editors and may be published after review and at the Editor's discretion. If appropriate, the comment will be paired with a reply from the authors of the Letter.

The Research Articles section continues to offer traditional scientific papers that present results and interpretations based on substantial research studies or critical reviews of ongoing research. Articles in this section are generally twenty to thirty journal pages long, with up to fifteen figures. They may be accompanied by a limited amount of supplementary online material where necessary. Such material should be as rigorously prepared and edited as is the main body of text. Time from initial submission of an editorially acceptable article to online publication would typically be $6-12$ months, with initial reviews obtained within $2-3$ months.

Notes and Comments is a new section of Boundary-Layer Meteorology that replaces the previous Research Note, and Comment and Reply sections. This section comprises occasional notes and comments on specific topics with no requirement for rapid publication. These short articles might include reports on incomplete research or revisits of earlier published work. Alternatively, the article in this section might be a comment on a published Research Letter or Research Article with a possible subsequent reply. Articles in Notes and Comments are limited to ten journal pages and include no more than five figures. A limited amount of supplementary online material may be included.

Book Reviews and Obituaries are two other article types that would be occasionally published in Boundary-Layer Meteorology.

To avoid delays at initial submission (very important when submitting a Research Letter) it is imperative that authors read the detailed Instructions for authors closely, carefully, and prepare the manuscript accordingly. The updated Instructions are readily available on the journal website. 